during the past fifty years, it is to be regretted that Reeves omits all mention of their study and interpretation. This would have formed the logical link between his competent summary of the principles of limnology on the one hand, and his discussion of the interpretation of past environments from the sediments of extinct lakes on the other hand.

The book is clearly and concisely written and profusely illustrated. It provides a very uscful compilation of present knowledge of the basins of extinct lakes in North America, with occasional illustrations from other parts of the world. It devotes much attention to what would appear to be one of Reeves' own particular interests, the study of the basins of pluvial lakes in arid parts of the United States, with reference to others in Africa and Australia. The emphasis being what it is, it is understandable that no examples from Europe are given, but it seems a real omission that no mention is made of the contribution to an understanding of Pleistocene climatic changes which is emerging from the study of existing ancient lakes such as Balaton, as well as some of the African lakes. In view of the limited field which is covered, the price of 130 shillings is high.

\section{WINIFRED TUTIN}

\section{BASALTIC ROCKS}

\section{Basalts}

The Poldervaart Treatise on Rocks of Basaltic Composition. By H. H. Hess and the lato Arie Poldervaart. Vol. 1: Pp. xvi +5 l2. 205s. Vol. 2: Pp. viii $+400+21$. 206s. (Interscience (Wiley): London and New York, 1968.)

These comprehensive tomes on rocks of basaltic composition form an elegant and appropriate tribute to their instigator, Professor Arie Poldervaart, although they do not, of course, necessarily represent his points of view on the numerous unresolved problems discussed. There are twenty-one authors and the quality of their contributions is high. There are twenty chapters. The descriptive, mainly qualitative, ones include those on forms and structures of extrusive and intrusive basaltic rocks, the petrography of basaltic rocks and rhythmic and cryptic layering in mafic and ultramafic plutons. Chapters dealing with quantitative aspects include those on physical properties, cooling and solidification of igneous rocks (applicable to acidic as well as basic rocks), mineralogy, geochemistry (major elements, minor elernents and isotopes), the origin and differentiation of basalt magmas, the problems of basaltic andesites and spilites, eclogites, the metamorphism of mafic rocks and the results of the laboratory approach on high pressure, water and oxygen effects on crystallization of basaltic magmas and silicate systems related to basaltic rocks.

Even with the diversity of subjects indicated by the chapter headings there is a little overlap and some inconsistencies. Chemical compositions and norms are considered in the petrography and geochemistry chapters while questions on the number and origin of basalt magmas are clearly in the minds of several authors. Differing views aro taken on high alumina basalts and different definitions of tholeiite occur in different chapters. Readers may be anxious to treat compositional data along the lines of Le Maitre in dealing with approaches to the chemical variations within and between volcanic rock series (J. Petrol., 9, 220; 1968).

The volumes contain authoritative and readable accounts on the results and state of research on basaltic rocks up to 1967 and their presence in a nearby library is desirable. Individuals who cannot afford their very high price will reflect that at least a few of the chapters may have historical rather than topical value in a year or two.

\section{NUCLEAR STRUCTURE}

\section{The Nucleus}

By Albert J. Dalton and Francoise Haguenau. (Ultrastructure in Biological Systems, Vol. 3.) Pp. xvi+244. (Academic Press: London and New York, April 1968.) $135 s 4 d$.

THis is the third volume in a serics dealing with the fine structure of biological systems. The series is not intended to provide comprehensive reviews of the title subjects but to survey those areas which have not recently bcen the subject of a general critique. The main topies, selected towards that end, for the present volume are on the whole well chosen, although it is unfortunate that it was not found possible to include a section on the morphological aspects of nucleocytoplasmic relationships. Some attempt has been made to compensate for this, however, in the editor's introductory note and it is also briefly referred to in the chapter by Hay.

The prefatory chapter by Allfrey is a short but most stimulating discussion of some of the chemical aspects of nuclear fine structure which serves to outline the current boundaries of knowledge in the field.

The first two chapters of the text proper, contributed by Hay and by Bernhard and Granboulan, are complementary. They together provide a good general description of structure/function relationships in the nucleolus of animal cells and although the two accourts frequently approach common ground there is, in fact, little duplication.

Hay begins the first chapter by describing the definitive features of nucleolar fine structure and goes on to deal with the nucleolar organizing chromosome and synthetic activities of the nucleolus. These deliberations are a necessary prelude to the second half of the chapter in which she covers the behaviour of nucleolar components during development. The discussions, which draw on work from a wide variety of species, are free of excessive detail, well balanced and develop a scheme of nucleolar events which extend from early oogenesis through to early embryogenesis. The final section of concluding rernarks is a most worthwhile addendum.

The earlier sections of the chapter contributed by Bernhard and Granboulan are concerned with the dynamic aspects of nucleolar ribonucleic acids and protcins and are based on results from fine structural cytochemistry and autoradiography. As is to be expected from the leading workers in this field, their presentation is thorough and up to date. In the section cntitled "Pathology of the Nucleolus" they describe the fine structural changes induced by a number of physical, chemical and viral agents; however, as in this arca much remains to be known about the functional significance of observed changes the section is largely descriptive.

Lafontaine's chapter on the plant coll nucleus is especially good concerning the fine structure of mitotic chromosomes and the nucleolus. Here again, care has been taken to avoid duplicating material which is presented in the other chapters of the book or has been recently reviewed elsewhere.

Finally, the fine structure of the centrioles and the mitotic spindle is described and discussed by Etienne de Harven. The author's treatment of this topic, which has not previously been the subject of such a wide ranging review, is comprehensive and authoritative. The chapter will be of importance not only to those concerned with the fino structural basis of mitosis but also to those primarily interested in cytoplasmic organization, as a description of the centriole and microtubular structures of non-dividing cells is also included.

Throughout the book the electron micrographs are of a high standard and are well reproduced. The references, which are an important feature of a book of this kind, are numerous and fully documented. 